\title{
Title: A possibility to square the circle? Youth uncertainty and the imagination of late adulthood
}

Author: Dr Valentina Cuzzocrea, Università degli Studi di Cagliari, Dipartimento di Scienze Sociali e delle Istituzioni, viale S. Ignazio 78, 09124, Cagliari (Italy). Email: cuzzocrea@unica.it

Acknowledgment: This is the draft of an article which has been accepted for publication in this form in April 2018 by the journal 'Sociological Research Online' (Sage) with the DOI: 10.1177/1360780418775123. The article is part of a project that has received funding from the European Union's Horizon 2020 research and innovation programme under the Marie SklodowskaCurie grant agreement No 665958 to conduct research at the University of Erfurt, as MWK (MaxWeber-Kolleg) Fellow. It also partially draws from research funded previously by 'P.O.R. SARDEGNA F.S.E. 2007-2013 - Obiettivo competitività regionale e occupazione, Asse IV Capitale umano, Linea di Attività l.3.1' at the University of Cagliari.

\begin{abstract}
Youth transitions literature has traditionally devoted great attention to identifying and analysing events that are considered crucial to young people regarding their (short term) orientation to the future and wider narratives of the self. Such categories as 'turning points' (Abbott 2001, Crow and Lyon 2011), 'critical moments' (Thomson et al. 2002, Holland \& Thomson 2009, Thomson \& Holland 2015, also used by Tomanović 2012) and 'crossroads' (Bagnoli \& Ketokivi 2009) have been used to identify and explain the events around which young people take important decisions in order to realise the so-called transition to adulthood, each suggesting a sense of rupture. This focus sits within a central interest of youth transition literature, namely to investigate what hinders or facilitates independence.
\end{abstract}

When looking more broadly at how young people imagine their future, however, taking a longer perspective opens insights not only in terms of ruptures, which these categories tend to refer to, but also in terms of the continuities that might also be very important in these narratives. Despite the methodological difficulties in getting young people to speak about their long term future, this paper seeks to discuss how they see their late adulthood through reflecting on how their narratives play out across different temporal horizons in order to establish their current priorities. Empirically, it is substantiated by essays on the future written by 18 -year-old students based in Sardinia, and discusses in particular an emphasis which they put on the long term as a term of fulfilment of their values.

Keywords: youth, uncertainty, narratives, Italy, turning points, time, transitions, critical moments, future, biographies. 


\section{Introduction}

Youth transitions literature has traditionally devoted a great deal of attention to identifying and analysing events that are considered to be crucial to young people regarding their short-term orientation to the future. Categories such as 'turning points' (Abbott 2001; Crow \& Lyon 2011), ‘critical moments' (Thomson et al. 2002, Holland \& Thomson 2009, Thomson \& Holland 2015, also used by Tomanović 2012), and 'crossroads' (Bagnoli \& Ketokivi, 2009) have gained momentum, considered in their potential to create new orientations. This scholarly interest is justified by the scope of youth transition studies itself, namely to investigate the processes which hinder or facilitate the attainment of independence.

However, looking more broadly at how young people imagine their future in a longer-term perspective - thus including a future further away in time - might open insights not only on how young people view themselves and their potential to attain independence, but also on how they view their societal and private role within that context, and the possibility of accomplishing present priorities. Therefore, this paper grapples with the challenge of considering more than one temporal dimension in young people's orientation to the future contextually, including their perspectives on late adulthood. This paper is empirically substantiated by means of essays on the future written by 18-year-old students based in Sardinia, and discusses in particular an emphasis on the long term as a moment for the fulfilment of their values.

\section{Time and youth biographies}

The experience of time and time transformations has often been of interest to social theorists (Nowotny 1994; Elias 1989; Bourdieu 1963; Rosa 2013; Adam 2005; Virilio 1986; Koselleck 1979). Building on this tradition of thought, the importance of studying temporalities in young people's lives and projections is also something which has received scholarly attention. Above all, the hegemony of linear time in the productive economy has been subject to critique (Leccardi 2013), meaning that individual navigation of the transition to adulthood is influenced by 
experience of time which can no longer be straightforwardly linear, or dictated by plans as 'organizing principles' (Leccardi 2005:124). Scholars have underlined a general crisis with the concept of life planning (Facchini \& Rampazi 2009, Reiter 2003) and with the linear model devised by Kohli (1986). An understanding of youth transitions as 'yo-yo' transitions (Biggart \& Walther 2005), in which there is often the possibility of a return, also has a strong temporal component to it. On a similar vein, the metaphor of 'shuffle generation' (Benasso 2013) has been used for the Italian case, which is the object of this article.

Despite these advancements in the field, there is a long way still to go if we want to unpack the theoretical, empirical and political underpinnings of temporalities within the different domains amongst which they are articulated (Woodman \& Leccardi, 2015: 56). Recently, Cook (2015) has explored how young adults relate to the long-term and more immediate future concurrently, with the intention of revealing intersections between immediate concerns and the ways that they approach their fears, hopes and imaginings of the long-term future. Arguing that 'an impossibly complex future has become subservient to an 'extended' or 'contracted' present in the face of the ever-increasing complexity of a relativized, pluralized society' (2015:715), she also makes two further points: the first is that previous research tends to concentrate mostly on only one dimension of young people's temporal perceptions, i.e. either present or future or past, neglecting the possibility of conceiving of them simultaneously. The second, is that in existing research plural dimensions of time are not necessarily normally brought together either with each-other or with the effects they may have in other domains (for instance, in the construction of a career).

These nodes are worth further investigation. In sum, scholarship has not reached substantial agreement beyond the general point that the temporalities to which youth refer are not homogeneous, and that envisioning a temporally distant future is difficult for them. Brannen and Nilsen $(2002,2007)$ argue that youth are particularly likely to experience what Nowotny (1994) calls an 'extended present'; here, 'time is perceived as accelerated, the future is enveloped by 'the 
here and now' and thereby 'loses its meaning, in the sense that people are unable to think about the long term, much less plan for it' (Brannen \& Nilsen 2002: 517). Similarly, in Reiter's words, young people 'are not able to survey past and future in the sense of an assessment of possibilities, chances and consequences of actions. They act and react in a limited sphere of pragmatic relevance and within a foreshortened horizon' (2003: 273). Acknowledging this argument, but trying to go beyond it, this article seeks to consider multiple intersections of temporal dimensions pertaining to short-term and long-term futures, and the possibilities which this offers within youth transitions.

A notable attempt to deepen these interconnections has been proposed by Adam through the concept of 'timescapes' (1995). She suggests that her perspective is able to illustrate which relationships, interdependencies and embeddedness are constitutive of one's experience- in the case of my research, young people's ways of looking at the future. This approach seems particularly useful in that it allows political underpinnings to emerge. It has been suggested that the future takes different shapes if we approach it from the standpoint of the present, that is, as 'present future' or from the standpoint of the future, i.e. as 'future present' (Adam \& Groves 2007:28). These two dimensions have very different action potential. This article seeks to add to the debate by suggesting that getting young people to talk about the long-term future tells us something of significance because such narratives necessarily have to pass through an effort to play with multiple time dimensions. I will show how this interplay offers overviews that a focus on turning points and a short term future alike does not, and allows to investigate insightfully broad orientations within the future and present lives of young people.

\section{Turning points: the right focus?}

'There is considerable diversity in the ways in which young people conceptualize and consider their futures. This variation derives from young people's present perspectives as they relate to particular lifecourse phases and 'moments' which young people are in the process of negotiating, 
V. Cuzzocrea- A possibility to square the circle? Youth uncertainty and the imagination of late adulthood-

and the ways in which their expectations are shaped by their gender, ethnicity and educational and other resources [...]'. (Brannen \& Nilsen 2002:520, my emphasis).

This quote exemplifies the dominant interpretation of young people's temporal orientations complexity, and provides theoretical grounds for studies on 'turning points' (Abbott 2001) and to structural constraints behind those. Much of this work is inspired by the concept of 'fateful moments' as life events having 'major implications not just for the circumstances [...] but for selfidentity' (Giddens 1991:43). In this sense, 'in contemporary lives fate does not imply fatalism, a full resignation to the given as a passive acceptance that events should be allowed to take their course. Rather, fate is met with suffering, resistance, coping, sense-making, haunting or escaping' (Bagnoli \& Ketokivi 2009:317). 'Crossroads', meanwhile, indicate 'concrete social settings and situations in which the different layers of human existence, fate, individual choice and the social, variously confront each other, together contributing to the unfolding of contemporary lives' (Bagnoli \& Ketokivi 2009: 318). In a similar sense, geographical mobility may be a crossroad (Cuzzocrea \& Mandich 2016): it can be imagined as an 'entry ticket' to embark on a better life that seems otherwise to be denied. Rather than prefiguring a scenario where difficulties are necessarily insurmountable, mobility therefore serves to enable 'youth agency'.

The idea of the 'turning point' has been treated as a key concept for analysing narratives of the self. As Andrew Abbott notes, turning points involve the redirection of paths, not simply the movement from one stage to another in a predictable trajectory. They 'relate to those [...] situations which have the effect of 'jolting' people 'into and out of trajectories' (Abbott 2001: 244, quoted in Crow \& Lyon 2011:18). In Crow and Lyon's analysis, turning points have been studied in that they 'revealed a certain hard-headed realism about the prospects for achieving ideal outcomes' (2011:18). Similarly, concepts such as 'transitions' and 'sequences' have also been proposed in order to describe the 'contingent life course' (Heinz 2003: 199), a concept that does 
not carry with it the latent meaning of continuity, such as that of 'switch trajectories' used to describe status passaged of Dutch youth (Du Bois Reymond et al 1994). In practice, a relevant question might be 'when, if ever, do you think these things might happen?' (as in Laughland-Booÿ \& Skrbiš’s work, 2014).

Drawing on the data collected for a UK based research project called 'Inventing Adulthoods', Thomson and colleagues suggest an operationalization of the 'fateful moments' that characterise Giddens' notion of the reflexive self(1991) labelling them 'critical moments'(Thomson et al.2002, Holland \& Thomson 2009; Thomson \& Holland 2015). Their 'working definition of a 'critical moment' is that of 'an event described in an interview that either the researcher or the interviewee sees as having important consequences for their lives and identities. Interviews were designed to allow 'critical moments' to arise in the narrative'. (Thomson et al 2002:339, my emphasis). These authors suggest 'critical moments' as a research strategy to see 'kind of events that were reported as having particular biographical significance' (2002:1, again, my emphasis) and 'compare narratives over time and across cases' (2015:2).

What is more interesting from their discussions for the present article, is that moments which emerged as critical were not necessarily always events related to the classic thresholds or markers in youth studies research (obtaining a job, concluding education, leaving the parents' house, eventually forming a couple and becoming parents) but events more related to the private: an episode of disclosing violence, a drug addiction emerging in a particular period of life, and so on. These findings suggest the need for a re-consideration of the important nodes in young people live, a topic which, it seems, has been somewhat under-researched.

This is especially important for the present discussion because there are elements of continuity in the narratives analysed in this article which are better visible when we look at how students see a future which is temporally distant, rather than at turning points which are necessarily closer in 
time. The turning points approach by its very nature tend to emphasise ruptures over continuities. But what if continuities were also important? And how can we see these continuities? To address these issues, this article seeks to pursue an integrated study of both the short and the long term in young people's narratives of the future and propose to reflect on methodologies which do not necessary overemphasise ruptures over continuities. Ultimately, this could also serve to make visible aspects other than those traditionally emphasised in youth transitions literature.

\section{The case study: methodology}

This article develops an analysis of part of the material originally collected for the research project Ifuture (Giovani, Cittadinanza e Capacità di Aspirare), funded by the Region of Sardinia (20122015) to investigate the narratives of the future that were produced among young Sardinians in order to understand how they seem able to identify and activate resources in their context. In the framework of an international fellowship on the themes of youth and temporalities (2016-2017), I developed this article in order to push forward the analysis of this material with special regard to wider theoretical and methodological underpinnings related to the experience of time. In particular, I seek to reflect here on a longer perspective for imagining the future and on how the findings emerging through this suggest the need for a discussion of what caveats emerges in the 'turning point' approach, of which I nonetheless share some important aspects, above all a biographical approach and an insightful attention to both agency and structure. While studying a future which is only imagined carries with it a fundamental difference with several studies on youth transitions, given that informants cannot refer to facts that have already happened, this method is here intended as to open insights which would otherwise difficult to explore.

Within western specificities (Hofmeister 2010), in Italy orientations to the future may be considered especially interesting given the scarcity of structural opportunities and severe uncertainty (Leccardi 2005; Bello \& Cuzzocrea 2018). The Sardinian case study needs to be seen 
within the specifics of its national context, but it has, in turn, strong cultural features (Arlacchi, 2007) that have become an object of a lively debate (Brigaglia 2017), which goes beyond an exceptionally high rate of youth unemployment (54\% vs. $42.4 \%$ nationally), and of NEETs more specifically ( $28 \%$ vs. $23 \%$ nationally). Between the end of the nineties and early two-thousands, the socio-economic conditions of the island were dominated by the hope and promise of the "new economy’ (Ferrucci \& Porcheddu 2004; Mongili 2015). These have produced specific societal mechanisms (Mandich 2009b) as well as specific experiences of temporality, which have been discussed in Italian literature (Mandich 2009a, Crespi 2005). However, socio-economic conditions have then become stagnant again. Taking into consideration, among other factors, the strong tradition of migration, at time resolving into a brain drain issue, projecting oneself towards the future may overall be seen by these young people as an impossible task -hence the expression 'squaring a circle'.

The visions of imagined futures analysed here are taken from essays written by 18 -year-old Italian students. The students were asked to imagine themselves at the age of 90 and to narrate their future lives in retrospect ${ }^{1}$. Existing scholarship emphasises the creativity of young people in reacting to uncertainty (Leccardi 2005, 2013; Spanò 2017; Colombo et al., forthcoming 2018). Brannen and Nilsen (2007) distinguish between the use of such terms as 'hopes' or 'ambitions'. The terms 'attitudes' (Grossin 1974) and 'future images' (Nilsen, 1999) are also used. But there is a paucity of research on how these develop in a medium to long term. In the material collected, temporal narratives assume a key role (Cuzzocrea 2018). Through imagining possible futures, young people discursively position themselves within society. The article reflects on the strengths of asking

\footnotetext{
${ }^{1}$ Students were asked to address this question: 'Imagine you are 90. Looking back at your life until that point, tell what happened to you. There is no need to invent something unlikely to happen. Simply tell the story of your life, how according to you it could have unfolded. Clearly, you cannot know what it's going to happen to you, but you could try and describe how things could go if things go how you think or you wish. Try and tell the whole of your life from the moment in which you finish school. Write as long as you think it's needed'.
} 
students to orient themselves towards a long-term future for the study of these narratives. The question posed to students was broad and did not ask students to focus on specific areas, as instead has been done in other pieces of research (Elliott 2010; Haukanes 2013).

Out of 341 essays, 253 were collected in Cagliari, and the rest in Nuoro. The gender ratio is 215 females (ca. 63\%) to 125 males (ca. 36\%) due to some of the chosen schools being predominantly female. Although the students were not asked to indicate their social background, it is still possible to infer some class-related aspirations (Cuzzocrea 2015) through their choice of school. The students were granted confidentiality, especially in relation to teachers, and that the essays would not be the object of evaluation. The lengths of the essays vary, from one paragraph to several pages. The texts, written in Italian, were translated into English by the author of this article only when required for quotation.

Similar methods of data-collection have been used in a range of other countries (Nugin 2014; Elliott 2010; Heggli et al 2013). Essays used as data resents several strengths, as well as challenges, at times dealt by researchers with art-based methods (Carabelli \& Lyon 2016). In an early phase of analysis, all essays were thematically coded using NVivo 10 and basic descriptive codes applied, which were then discussed within a small research team. Students were invited to an open day in one of the schools (in which they participated eagerly) at which preliminary findings were presented and discussed. Some of the classes were later involved in follow up focus groups, the analysis of which is not included in this article. In the following section I start discussing empirical findings and while I do so, I illustrate why I see the temporal observations of this article to have broad political implications, drawing in particular from 'Future Matters' (Adam \& Groves 2007). 


\section{Past, future, and possibilities of action}

The decisions which individuals make in the present have a pivotal impact on the structure of future society: whether or not to have children, for instance, both depends on how the conditions for them to grow up are perceived and will have an impact on future demographics. Whether or not to enrol university also has strong implications for the education levels of the adults of tomorrow (see Aynseley \& Crossouard 2010). In this sense, the imagination of the future shapes not only the future, but also the present. The imagination of the future can in turn be seen as in the intersection between agency and structure, which to some extent 'critical moments' are apt to investigate.

In Adam and Groves' work, the relationship between action, knowledge and ethics is made explicit (2007: xiv). While political debates often use the argument that young people are pivotal for the future of a nation (or city, or political party etc), the distinction between future present and present future, which they suggest, is not sufficiently elaborated. Moreover:

it makes a difference to our action potential whether the future is conceived as pre-given and actual, as empty possibility, or as process realm of latent future in the making'. [...] If the future is seen as ours for the making and taking, then imagination may be employed for conjecture, creation, colonization and control' (2007: 164).

It is therefore important to examine which biographical temporalities seem more pressing for young people, their choice of which to draw more upon in their narratives is not irrelevant. In the material collected, students were asked to imagine approximately 70 years of their future life. A lot of anxieties, wishes, emotions and dilemmas open and close the narratives, and some narratives may reveal relatively little about the actual events the authors imagine will happen in their lives. The students frame their essays as secret diaries; they imagine the telling of stories to 
grandchildren, or the discovery of old photos which prompts the start of a narrative. Anything we can broadly think of as strategies, are concentrated in telling the period of life when they leave school and get settled, namely before the age of thirty (Cuzzocrea, forthcoming). Narratives are particularly empty between the ages of thirty and sixty: nothing terribly interesting seems to happen in this period, and the 'path' is usually decided before the narrator reaches 30 , whilst a lot of details about activities (and feelings) are concentrated around the later period, after retirement. It is perhaps surprising that so much space is dedicated to describing life between the ages of 60 and 90 . While as researchers we might hope to see, through the eyes of young people, recognisable occurrences and situations, it becomes evident that the narratives which the students produced on their own - in most cases with earplugs to better isolate themselves from their peers and friendsoverall may say more about values they believe in than about factual details or turning points. In the Sardinian narratives, the struggles implied in imagining a future seemed to vanish at a certain point in time, like in this except where a female student refers to an accomplishment which she finally realises through her grand-daughter:

'Now I am 90 I am retired and I am really satisfied with my life, I became fully accomplished in my job and I have a beautiful family. Not everything has been rosy, there have been moments of crises where it was necessary to cut expenses but in the end I have found contentment. My sons/daughters work and you, little granddaughter, are continuing along my path of study and this is for me a great satisfaction' (TF F 67)

We are therefore here faced with the question of how they can manage to square the circle of their lives and give the composition a 'finished' touch. For Leccardi, the past might be a source of certainty (2013). My suggestion is that the creative narrative forms chosen might disguise precisely a difficulty in dealing with uncertainty. While turning points are supposed to be followed 
by discrete periods of life, it is not necessarily so. If, rather than looking at turning points, we look at the full imagined story of their life, we could maybe depict a (partially) different scenario. In fact, the emphasis on turning points may not leave enough room for displaying continuity, should they want to narrate such a dimension too. As researchers, we should also be concerned with being able to make continuities visible if narratives suggest so, and more generally, with thinking at their role next to that of discontinuities and ruptures. Indeed, in the last development of their work on critical moments, Thomson and Holland too warn that recognising critical moments 'was not a straightforward matter' in that they 'discovered tensions between what young people might present as a critical moment and what [they] as researchers might identify as important' (2014: 726).

For Reiter, 'the future remains uncertain because no long-term temporal structure can be built up at all (2003: 267). ${ }^{2}$ But this suggestion does not seem to explain the endpoint of the narratives here analysed. In a seminal article dated 1980, Alessandro Cavalli distinguished between youth as a stage and youth as a process, arguing that due to socio-economic changes, the first is in the process of replacing the second:

'While a process is a complex of practices oriented to a precise predictable aim, a condition is a situation in which one waits for an outcome which is not predictable. This unpredictability depends on the basically infinite number of possible outcomes, some sufficiently known (and, often undesirable), other only vaguely perceived, others totally unknown but of which one can feel the remote existance. In this situation it becomes almost impossible to choose for at least three reasons: on the one hand one does not know well the available options, on the other there is no clarity on the paths which bring to the realization of different options, and, finally, one sees,

\footnotetext{
${ }^{2}$ Emphasis is mine.
} 
V. Cuzzocrea- A possibility to square the circle? Youth uncertainty and the imagination of late adulthood-

unclearly or with awareness, that any strategy of behaviour adopted today is scarcely connected to determining outcome that should take place in the future'. (Cavalli 1980:524, my translation).

The impossibility of choosing, which for Cavalli is part of the condition of being young, in theory contrasts with a search for turning points. If the process of taking a decision is difficult, perhaps the heuristic salience of turning points has been exagerated, particularly in the conditions of even greater uncertainty that form a part of current societal patterns. It is legitimate to ask whether in this respect too we as researchers tend to exagerate an emphasis that is not so crucial in young people's narratives and ultimately whether the methodological challenges emerging when working on the theme of the future should indicate an openess to an alternative focus.

\section{6. 'Squaring the circle' of uncertainty}

In this section of the paper, I turn to discussing the ways in which a long-term temporal perspective illustrates an effort to square the circle of one's life, and the forms which this takes. By using this expression I wish to emphasise that beyond the normality that emerges from young people's imagination of the future, it is possible to see how difficult it is for them to solve the node of projectuality and strategic thinking. If, in this situation, it is not always possible to see turning points, imagining how their life can unfold in the long term may become somehow easier. This is how a female student talks about her everyday life as a pensioner:

'Experiencing it myself then, I realised that being retired entailed a routine just like I had always had: when I was young I would go to school every day, in the same room, and see the same faces everyday; when I was at work, I would go in the same office every day, even during bank holidays; now that I am retired, I see the same groceryman and the same butcher; do the same things every day: get up early, go shopping, clean the house and care for my grandchildren'(CL F 38). 
V. Cuzzocrea- A possibility to square the circle? Youth uncertainty and the imagination of late adulthood-

Yet, however unexpected this focus on similarities in routines may seem, it delves into what Facchini and Rampazi refer to as 'reflected uncertainty', namely an idea of 'suspension' in order to express the 'ambiguous effects of young people's biographical uncertainty on late adults' own perspective' (2009:352).

Reference to existing normative frameworks and, in particular, to the life of parents, has already been noted (Andres and Wyn, 2010). As Mandich stresses from the same data I focus here on, thinking about the imagined future through the lens of retirement allows young people to enunciate a happy ending of some sort. Indeed, the term enjoy (the Italian term is godere) is 'quite often used to describe life after retirement and often associated with adverbs such as finally or at last to express a strong sense of relief mixed with satisfaction' (Mandich forthcoming 2018: page). In another article, I have discussed how youth aspire to keep a contact with the island throughout the years (Cuzzocrea, forthcoming). A student eloquently says that she 'wanted to leave to come back. To leave to learn and improve my land which I loved and I still love' (CL F 17). Therefore, looking at a lifetime temporal perspective allows us to see envisaged returns, as well as more imminent departures. In this late future, 'the start of possible re-engagement activities is delayed as they may contrast with the economic, temporal and affective commitments essential in continuing to provide support for the children' (Facchini \& Rampazi 2007:357), and the long term brings relief. More generally, an emphasis on values and family is certainly a crucial element in experiencing continuities within these essays, as both of the following essays suggest, even if one of them departs from a positive experience and the other one does not:

'Now that I am retired I enjoy [staying with] my family' (TF F 56).

'Even if I have been through some terrible moments I have always been able to make it through alone and I have used my life to work for my children, to give them something I have never had. I have taught them that in life nobody gives us something for free and if we want something we have 
V. Cuzzocrea-A possibility to square the circle? Youth uncertainty and the imagination of late adulthood-

to sweat to earn it. Now I can enjoy retirement even if I am always ready to give a hand to my children should they need anything from me'. (TF M 23, my emphasis)

Continuity itself is depicted in terms of values. It is the valorial dimension, in other words, that keep one's autobiography together in the long term, defined as the whole of things that count to them -family and meaningful relations above all. A recent study on parenting- and, becoming a parent is a turning point par excellence- has also shown that a turning point itself may be seen through the relational continuities it ensures (Franceschelli et al 2017). The journey of one's life is not easy and only at the end can it be seen as actually reaching fulfilment:

'Now that I am ninety, I still remember that feeling that I had when I finished university, the awareness that I had all my life ahead of me and at the same time the fear of knowing how my life could have gone. Now that I am old, I wish I could go back and reassure that girl, because I do not regret any of the decisions that I have taken and that have led me where I am now'. (CL F 33)

Such narrative forms allow difficulties to solve themselves at some point in life, without necessarily having to figure out and enact active strategies:

'I am in fact proud of both my daughter, but also of myself, because together with my husband we made things in such a way that all her dreams are able to come true, exactly as my parents did with me. They broke themselves into pieces to make me happy and allow me to become the best paediatrician in the whole Cagliari. I have been a good mum, and now that I am ninety I am an excellent grandma, who at night goes to bed late to make crochet for grandchildren. Oh my god, it is now very late, I have to go to collect Aurora and Daniele from school'3. (TF F 69)

${ }^{3}$ She is imagining to be writing while it is time to collect her grandchildren from school, suggesting an image of her still 'in action'. Names of the grandchildren contribute to give a 'reality' touch to her narrative. 
V. Cuzzocrea- A possibility to square the circle? Youth uncertainty and the imagination of late adulthood-

At times, continuity emerges through a nurturing of the same passions over time. For RAG F 15, it means continuing caring for cats, and playing with grandchildren, naming them after characters from Harry Potter, her passion since she was a child. For TF F 73, it means thinking again about the motorbike parked in the garage which has kept her and her husband together, along with a group of friends 'with the same dream and the same passion' who are all members of a local motorbike lovers club (that she mentions by name). For RAG M 17, it means continuing to search for old cars and motorbikes to renovate with his cousin, 'his peer and (life) partner since the earliest years of his life'. Such lines of continuity may be so strong that one lifetime is not always enough to fully realise them. In these cases, we see that the same values are transmitted to sons and daughters:

I retired towards the age of 70 - now I do not remember-but my son was grown up already, and I saw myself in him, it looked to me as if I was re-living the spirit of my youth' (RAG M 13).

'Now that I am an old woman who feels young inside, I am retired and I have left my two beloved shops to my daughter and my grand-daughter. I am always cheerful and smiling for once, happy with all I have and I would not change anything that has been part of my life'. (TF F 102)

Over the course of one's biography, such continuities on the one hand, and family and values on the other, are strictly related:

I kept on working until the age of seventy- two, I got good pension, and I understood that in my life I was right to commit and not to give up in face of the many challenges that life reserved for me. Now at the age of ninety I am happy, I am enjoying old age with my wife, we live happily and on Sundays we welcome my son's family. Now he is also a man and he never gave up, as I haven't given up either, life taught me never to give up: I looked for a job in one of the worst crises ever, and over time I managed to find it, it was not a great job but I managed to be content with that and I clenched the teeth. In life you can never give up, you always have to fight, maybe I fought a 
V. Cuzzocrea-A possibility to square the circle? Youth uncertainty and the imagination of late adulthood-

bit more than other people who looked for a job at other times, but it does not matter, because all that matters is the happiness that I read in my eyes every time I look at myself in the mirror' (RAG M 16).

In several cases, this continuity takes the form of economic activities which are passed down across generations:

'At the age of 65 I retired and I left my (dentistry) business to my daughter Nicole who decided to follow in my footsteps. I got her to work with me as soon as possible, and I taught her techniques and ways to behave: she was a little me. [...] We spend our old age in the attic we dreamt about when we were kids' (TF F 36)

Also, I have elsewhere discussed (Cuzzocrea 2015) that the wish to embrace a medical profession could be seen, in a selection of these essays, as an indication for wanting to continue to occupy a middle class occupation, rather than as a specific professional orientation.

In sum, looking at a future which is distant in time allows a squaring of the circle of one's life. It is used as a normative strategy to give evidence of how they have been successful in overcoming difficulties:

'At the age of 65 I retired, and certainly tiredness ceased, but loneliness increased. My daughter opened a dance school, and I was full of joy because she realised a desire that it had previously been mine. [...] The main sadness was stopping dancing, but seeing my daughter dancing has always warmed up my heart, as if I was the one moving' (CL F53).

There is very little of the extra-ordinary in these accounts, as in other studies (eg Andres and Wyn, 2010). On the contrary, they can be interpreted as exceptionally ordinary (Mandich, forthcoming). In the absence of criteria for making decisions or of particular life-details to hold on to, the young 
people involved in the study perhaps draw such ordinariness simply from looking at their parents. Such a mechanism is already depicted in literature, however it is described in contrast to a youthful phase, where more interesting things are happening:

'[Young women] consider their parents' lives to be 'boring' and 'routine' which they contrast with their own present lives as young people which they consider ought to be full of possibilities, variety and excitement' (Brannen \& Nilsen 2002:522).

In this study based on data from several European countries, adulthood is kept 'at a bay', in a distant future, in virtue of the responsibilities it implies. In the Sardinian case, though, the timings of one's life tends to be assimilated, rather than separated, and so continuities are overemphasised over ruptures. Continuities are purposively used, in the narratives, to emphasise a sense of satisfaction and achievement that will arrive at some point, despite the difficulties of the present:

'Looking at the signs of time, of which my face is testimony, and reflecting on the woman I became, I can say I have fully exhausted these 90 years, but I have done so with a job which gave me a lot of happiness and whilst raising my daughter to the best of my abilities, making me proud of myself' (TF F 33)

The emerging question is therefore how it is possible to understand this within the existing theoretical framework. Brannen and Nilsen's study leads to the identification of three distinct decision-making models: a model of deferment, in which those with an 'extended present' orientation seek to postpone all consideration of adulthood and its associated responsibilities; a model of adaptability, in which individuals made short-term, mutable plans for a future they regard as constantly subject to change; and a model of predictability, in which individuals view their life pathways as clearly laid out before them in accordance with tradition (2002). In a study published 
in 2014, Carmo et al. argue that young Portuguese workers project their professional future either through cumulative or non-cumulative projections, and that this latter category can be divided into three subtypes: contingency, immobility and rupture; 'the future is not predictable because the present is constantly changing', they argue (2014: 350). This study also makes a somewhat 'traditional' distinction between past, present and the future, separating them out.

But if the link between past, present and future is to be problematised (Baizerman \& Magnuson 1996), a general view, such as Giddens' (1991) notion that in late modernity individuals reflexively 'colonise' their future, perhaps assumes a different meaning. In light of the material analysed in this article, the imagination of the future seems to have a focus which is rather unbalanced with respect to those areas that are more centred on the self (one's values, who one wants to be) rather than on strategies, facts and outcomes of the capacity for action and ultimately, turning points. The imagination of the future emerged here is centred on continuities (what young people aspire to keep throughout the years) rather than on cleavages and interruptions (what they may get as result of achievements and directions). This seems valid even in those cases when mobility is involved (Cuzzocrea, forthcoming). This finding suggests the need to reconsider not only the long-term perspective as capable of revealing insights within youth self-narratives, but also the very concept of youth itself through the ways temporalities are played out, in the short as well as in the long-term.

\section{Conclusions}

In this article I have discussed how young people's orientation to the future is interconnected to several temporal dimensions of the future, and how looking at a longer term perspective something overlooked in existing literature on youth transitions- can in fact highlight interesting views on how young people see themselves in what can be considered a structurally difficult present. Within this perspective, strong elements of continuity emerge, rather than the elements of 
rupture which are predominantly sought by a research focus on turning points in young people's narratives. Looking beyond the idea of ordinariness that is contained in several narratives of imagined future analysed (especially those that are not tied to mobility, Cuzzocrea \& Mandich 2016), the long-term view allows youth to express dimensions of continuity of the self, and serves to keep uncertainty under control, explicating conditions for an 'happy ending':

'Last photograph: ${ }^{4}$ it portrays me while I receive from the medical association a medal for my retirement, and this gives me the cue for some reflections. I can state that I am satisfied with my life and the choices I made to live happily and in harmony with myself, realising my ideals'. (CL M 52).

Looking at a distant future allows individuals to express what values matter for them and in so doing allows them to square the circle of an otherwise, very uncertain life-course. I wish to stress not only the heuristic relevance of these arguments (which are able to underline what is important for young people) but also the methodological relevance (reflecting on the types of imagined narrative that are collected though a written form) and, last but not least, a more broadly political aspect. It is in the possibility of finding themselves as they wish to continue their lives that these narratives acquire coherence and continuity. In a context of economic depression, the values that they can express allow them to hold on to themselves. Often, at the stage of being asked to write an essay about their future, they may simply not be able to identify turning points, and the ruptures that these presuppose. Turning points, moreover, may be frightening, especially when anticipated as future events. It is for this reason that while they may be able to open perspectives, they must also be handled carefully in the data collection and interpretation.

\footnotetext{
${ }^{4}$ This student is imagining telling the story of her life though looking at old photographs and commenting on them to an interlocutor, i.e. the reader of the essays.
} 
While this point of view partly diverges from the majority of existing literature on youth transitions, interestingly it converges with a study on middle-aged Italian women (Facchini \& Rampazi 2009). In Facchini and Rampazi's study, 'continuity is tied to the idea of 'personal growth' which is attained by learning how to deal in the present with complexity and the unexpected in an individual life context [...]'; and, 'the idea of duration is reconstructed on the basis of the continuity of relationships, instead of roles and careers' (2009: 353). To interpret this finding, Facchini and Rampazi use the expression 'reflected uncertainty', namely a 'suspension' (2007:357). This goes in a similar direction to Leccardi's observation that 'the vast majority of young people are [...] well aware of the indissoluble link between past, present and future' (2013: 264). While I would not take for granted self-awareness in linking these dimensions, these connections must be powerfully present as so many aspects of the past emerge clearly in the imagination of the future, especially a future which is further away in time. And this is worth examining in relation to how young people see the present and act in the present, ultimately reminding us that reflecting in terms of 'future present' and 'present future' reveals interconnections and possible ambivalences alike.

\section{References}

ABBOTT, A (2001) 'On the concept of turning point' ch.8 in Time Matters: On Theory and Method. Chicago: University of Chicago Press, p. 240-260.

ADAM, B (2005). Time. Polity Key Concepts Series. Cambridge: Polity Press.

ADAM, B E and Groves, C R (2007). Future matters: action, knowledge, ethics. The Study of Time / Supplements, Vol. 3. Leiden: Brill.

ANDRES, L and Wyn, J (2010) The Making of a Generation: The Children of the 1970s in Adulthood, University of Toronto Press, Toronto. 
V. Cuzzocrea-A possibility to square the circle? Youth uncertainty and the imagination of late adulthood-

AYNSLEY, S and Crossouard, B (2010). 'Imagined futures: why are vocational learners choosing not to progress to HE?', Journal of Education and Work, 23(2): 29-143.

ARLACCHI, P (2007). Perchè non c'è la mafia in Sardegna. AM\& D Edizioni, Cagliari.

BAGNOLI, A and Ketokivi, K (2009) 'At a crossroads. Contemporary lives between fate and choice', European Societies, 11(3): 315-324.

BAIZERMAN, M L and Magnuson D. (1996). 'Do we still need youth as a social stage?', Young, 4, p. 234-245.

BELLO B G, CUZZOCREA V (2018), 'Editorial: introducing the need to study young people in Italy', Journal of Modern Italian Studies, 23(1): 677-683.

BENASSO S, (2013) Generazione shuffle. Traiettorie biografiche tra reversibilità e progetto, Aracne, Roma.

BRIGAGLIA, M (2017). Viaggio in Italia. La Sardegna. Il Mulino, 31 may 2017.

BIGGART, A and Walther A (2006) Coping with Yo-Yo-Transitions: Young Adults' Struggle for Support, between Family and State in Comparative Perspective', in Leccardi, C and Ruspini, E (eds) A New Youth? Young People, Generations and Family Life, 41-62. Farnham: Ashgate.

BOTTERILL, K (2014) 'Family and Mobility in Second Modernity: Polish Migrant Narratives of Individualization and Family Life', Sociology 48(2): 233 - 250.

BOURDIEU, P (1963) 'La societè traditionelle. Attitude à l'egard du temps et counduite èconomique', Sociologie du travail, 1(S), p. 24-44.

BRANNEN, J and Nilsen A (2002) 'Young People's Time Perspectives: From Youth to Adulthood', Sociology 36(3): 513-37.

BRANNEN, J and Nilsen, A (2007) 'Young People, Time Horizons and Planning: A Response to Anderson et al.' Sociology 41(1): 153-60.

CARABELLI G, and Lyon D (2016) 'Young people's orientations to the future: navigating the 
present and imagining the future'. The Journal of Youth Studies 19(8): 1110-1127.

CARMO R M, Cantante F, de Almeida Alves N (2014) 'Time projections: Youth and precarious employment', Time \& Society 23(3): 337-357.

CAVALLI, A (1980) 'La gioventù: condizione o processo?', Rassegna italiana di sociologia, 4: $519-542$.

COOK, J (2015) 'Young people's strategies for coping with parallel imaginings of the future', Time \& Society, (25) 3: 700 - 717.

COLOMBO, E, Leonini L, and Rebughini, P (2018) 'A generational attitude: Young adults facing the Economic Crisis in Milan', Journal of Modern Italian Studies, 23(1): 61-74.

CROW, G and Lyon D (2011) 'Turning points in work and family lives in the imagined futures of young people on Sheppey in 1978', Young lives and imagined futures: insights from archived data. Timescapes Working Paper Series, 6: 12-26.

CUZZOCREA V (forthcoming) 'Rooted mobilities in youth's narratives of the future', Current Sociology.

CUZZOCREA V (2018) 'Moratorium or waithood? Forms of time taking and the changing shape of youth', ifirst in Time \& Society.

CUZZOCREA V, MANDICH G (2016) 'Students narratives of the future: imagined mobilities as forms of youth agency?', Journal of Youth Studies, 19(4): 552-567.

CUZZOCREA V (2015) 'Imagining a future in the medical profession: Gender and Young Sardinians' Narratives of a Career in Medicine, Gender, Careers and Inequalities in Medicine and Medical Education: International perspectives, ed. by Maria Tsouroufli, Emerald Publishing, p. 177-201.

DU BOIS-REYMOND M, Guit H, Peters E, Ravesloot R and Van Rooijen E (1994) 'Life-course transitions and future orientations of Dutch youth', Young, 2 3-20. 
V. Cuzzocrea- A possibility to square the circle? Youth uncertainty and the imagination of late adulthood-

ELLIOTT, J (2010) 'Imagining a Gendered Future: Children's Essays from the National Child Development Study in 1969', Sociology 44(6): 1073-1090.

FACCHINI, C and Rampazi, M (2009) 'No longer young, not yet old. Biographical uncertainty in late-adulthood temporality', Time \& Society 18 (2/3): 351-372.

FERRUCCI, L and Porcheddu D (2004) La new economy nel Mezzogiorno. Istituzioni e imprese fra progettualità e contingencies in Sardegna. Bologna: Il Mulino.

FRANCESCHELLI, M, Schoon, I and Evans, K (2017) 'Your Past Makes You Who You Are': Retrospective Parenting and Relational Resilience Among Black Caribbean British Young People, Sociological Research Online, 22(4): 48-65.

GIDDENS, A (1991) Modernity and Self-Identity. Cambridge: Polity Press.

GROSSIN, W (1974) Les temps de la vie quotidienne. La Hayc: Paris.

HAUKANES, H (2013) 'Belonging, mobility and the future: Representations of Space in the Life Narratives of Young Rural Czechs', Young 21(2): 193-210.

HEGGLI, G, Haukanes H, and Tjomsland M, (2013) 'Fearing the future? Young people envisioning their working lives in the Czech Republic, Norway and Tunisia', Journal of Youth Studies, 16(7): 916-931.

HEINZ, W (2003) 'From Work Trajectories to Negotiated careers. The Contingent Work life course', in Handbook of the Life course, ed by Jeylan T. Mortimer and Michael J. Shananan Kluwer Academic/Plenum Publisher, New York, p. 185-204.

HOFMEISTER, H (2010) 'Life Course', in Handbook of European Societies, edited by Stefan Immerfall, Göran Therborn, Springer, New York, p. 385-411. 
HOLLAND, J and Thomson, R (2009) 'Gaining perspective on choice and fate: revisiting critical moments', European Societies, 11(3): 451-469.

KOHLI, M (1986) The World we forget: a historical review of the life course. In V. W. Marshall (ed.) Later life: The social psychology of aging Beverly Hill, CA: Sage, p. 271-303.

KOSELLECK, R. (2004, ed or 1979) Futures past. On the semantics of historical time, Columbia University Press, New York.

LAUGHLAND-BOOŸ J, Skrbiš Z, (2014) 'Whose choice? Young people, career choices and reflexivity re-examined', Current Sociology, 63 (4): 586 - 603.

LECCARDI, C (2013) 'Temporal perspectives in de-standardised youth life courses', in Handbuch Uebergaenge ed by Schroeder, Stauber B, Walther A, Boehnisch, Lenz.

MANDICH, G (forthcoming 2018) 'Dreams of ordinariness: The 'missing middle' of youth aspirations in Sardinia', in Campbell P, Harrison L, and Hickey C., eds. Young People and the Politics of Outrage and Hope, Brill (Leiden and Boston).

MANDICH, G (2009a, eds) Quotidiano flessibile. Usi e rappresentazioni del tempo nella Sardegna della new economy. Cagliari: AM\&D Edizioni.

MANDICH, G (2009b) Oltre la tradizione. Una Sardegna post-convenzionale? CUEC (Cagliari) MONGILI, A (2015) Modelli di innovazione e politiche dell'innovazione. Il caso del Parco scientifico e tecnologico della Sardegna, in Topologie postcoloniali Innovazione $e$ modernizzazione in Sardegna Cagliari: Condaghes.

NILSEN, A (1999) 'Where is the Future? Time and Space as Categories in the Analysis of Young People's Images of the Future', Innovation. European Journal of the Social Sciences, 12(2): 17594. 
NOWOTNY, H (1994) 'Time: modern and postmodern experience', Cambridge, UK: Polity Press; Cambridge, MA: Blackwell Publishers, 1994.

NUGIN, R (2014) 'I think that they should go. Let them see something'. The context of rural youth's out-migration in post-socialist Estonia', Journal of Rural Studies, 34: 51-64.

PRINCE, D (2014) 'What about place? Considering the role of physical environment on youth imagining of future possible selves', Journal of Youth Studies 17(6): 697-716.

REITER, H (2003) 'Past, Present, Future'. Young 11(3): 253 - 279.

ROSA, H (2013) Social Acceleration: A New Theory of Modernity. New York: Columbia University Press.

SPANÒ, A (ed, 2017) I giovani del sud di fronte alla crisi: Strategie di sopravvivenza e capacità di innovazione. Milano: Franco Angeli.

THOMSON, R and Holland, J (2015) Critical moments? The importance of timing in young people's narratives of transition. In: Wyn, Johanna and Cahill, Helen (eds.) Handbook of children and youth studies. Springer Singapore, p. 723-733.

THOMSON, R and R. Bell, J. Holland, S. Henserson, S. Mcgrellis, S. Sharpe (2002), 'Critical Moments: Choice, Change and Opportunity in Young People's Narratives of Transitions', Sociology, 36(2): 335-354.

TOMANOVIC, S (2012) 'Agency in the Social Biographies of Young People in Belgrade', Journal of Youth Studies, 15(5): 605-620.

VIRILIO, P (1986) Speed and Politics: An Essay on Dromology, trans. M. Polizzotti. New York: Semiotext.

WOODMAN, D and Leccardi C (2015) Generations, transitions, and Culture as Practice: A temporal approach to youth studies, in 'Youth Cultures, Transitions, and Generation. Bridging the Gap in Youth research', ed by Woodman, D and Bennett, A, Palgrave Macmillan. 